\section{Medullary Carcinoma of Breast}

SIR,-While agreeing with Dr. H. J. G. Bloom and others (25 July, p. 181) that the results of radical treatment for medullary carcinoma of the breast are remarkably good we cannot accept the validity of two of their conclusions.

Firstly, there is insufficient evidence to support their view that conservative treatment would not have achieved similar results as compared with a radical approach. In their non-randomized retrospective study only 14 patients out of 104 had either a simple mastectomy or wedge excision. Of these 10 also had postoperative radiotherapy. No attempt was made to explain why the policy of radical surgery was abandoned in these cases. We believe that it is not possible to reach a reasonable conclusion on the results of conservative surgery alone on the basis of four patients.

Secondly, we feel that it is very difficult for the authors to make judgements on the importance of the role of possible local defence mechanisms in medullary carcinoma of the breast. This would entail a prospective randomized trial comparing the results of radical treatment, which would involve ablation of the lymph nodes by surgery or radiotherapy, with conservative surgery by itself, which would result in the least interference with regional lymph nodes.

Taking cancer of the breast as a whole there is increasing evidence of the importance of local defence mechanisms. ${ }^{1}$ We would agree wholeheartedly with Dr. Bloom and his colleagues when they say that the value of treating the axilla in the initial therapy of early breast cancer awaits the results of well-conducted clinical trials where the comparison of radical and conservative therapy can be made on secure foundations. ${ }^{1-W e}$ are, etc.

Michael Baum. M. H. EDWARDS.

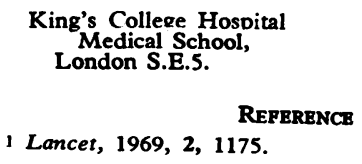

\section{Contraceptives and Serum Proteins}

SIR,-We have read with interest the recent report by Dr. L. W. Powell and others (25 July, p. 194) who have shown that single intramuscular injections of 300 mg. medroxyprogesterone acetate, lasting 120 to 180 days, do not affect serum levels of iron or total iron-binding capacity (T.I.B.C.). This is in contrast to similar women receiving various "sequential" oral contraceptives who showed marked increases in these serum components. On the basis of this difference, Dr. Powell and his colleagues suggest that the elevations in serum iron and T.I.B.C. seen in women taking sequential or combined oral contraceptives are due to the oestrogenic rather than the progestogenic component. They further propose that any effect of the progestogen is due to oestrogenic metabolites from the particular compound used, and that "pure" progestogens, such as medroxyprogesterone acetate, which have no oestrogenic metabolites, are devoid of effect.

As these findings are somewhat in contrast to previous studies by ourselves and

\begin{tabular}{|c|c|c|c|c|c|c|c|c|}
\hline \multicolumn{5}{|c|}{ Steroid } & \multirow{2}{*}{$\begin{array}{c}\begin{array}{c}\text { Daily Dose } \\
\text { Mg. }\end{array} \\
-\end{array}$} & \multirow{2}{*}{$\begin{array}{c}\begin{array}{c}\text { Serum Iron } \\
\mu \mathrm{\mu g} . / 100 \mathrm{ml} .\end{array} \\
93 \pm 25\end{array}$} & \multirow{2}{*}{ 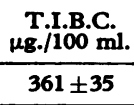 } & \multirow{2}{*}{ 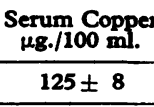 } \\
\hline None $\quad$. & .. & .. & .. & .. & & & & \\
\hline Ethinyloestradiol & .. & .. & .. & .. & $\begin{array}{l}10 \\
20 \\
50\end{array}$ & $\begin{array}{l}95 \pm 28 \\
96 \pm 31 \\
90 \pm 30\end{array}$ & $\begin{array}{l}355 \pm 38 \\
359 \pm 32 \\
365 \pm 40\end{array}$ & $\begin{array}{l}136 \pm 10 \\
181 \pm 16 \\
227 \pm 18\end{array}$ \\
\hline Norethisterone Acetate & & .. & .. & .. & $\begin{array}{r}300 \\
1000\end{array}$ & $\begin{array}{l}118 \pm 21 \\
119 \pm 30\end{array}$ & $\begin{array}{l}428 \pm 49 \\
425 \pm 51\end{array}$ & $\begin{array}{l}130 \pm 8 \\
152 \pm 11\end{array}$ \\
\hline $\begin{array}{l}\text { Ethinyloestradiol + } \\
\text { Norethisterone Acetate }\end{array}$ & & $\because$. & .. & . & $\begin{array}{r}50 \\
+1000\end{array}$ & $122 \pm 28$ & $465 \pm 65$ & $235 \pm 25$ \\
\hline d(l)-Norgestrel & $\cdots$ & .. & .. & .. & 1000 & $118 \pm 25$ & $432 \pm 42$ & $128 \pm 10$ \\
\hline
\end{tabular}

Mean Values \pm S.D.

others ${ }^{1-t}$ and as the matter is of some complexity and open to a number of possible interpretations, we thought we would present the preliminary results of a study, as yet unfinished, in which we have given oral oestrogen and progestogen separately and in combination to groups of 10 to 12 healthy young women who had not previously received steroids of any kind. Results are shown in the Table. The compounds were given in gelatin capsules or as proprietary preparations daily for three to four weeks. Each patient served as her own control. Assay methods and other techniques are as given in our previous publications. ${ }^{15}$

These results indicate that a combined oral contraceptive containing ethinyloestradiol $50 \mu \mathrm{g}$. and norethisterone acetate 1,000 $\mu g$. (that is, Minovlar) produces a significant increase in all three serum values, but that ethinyloestradiol, given alone in doses up to $50 \mu$. daily, significantly increases serum copper values but not serum iron or T.I.B.C. In contrast, norethisterone acetate has a marked effect on serum iron and T.I.B.C., but only a slight action on serum copper. The other progestogen used in this study, d(j)-norgestrel, is the 13-homologue of norethisterone, but unlike the latter is virtually free of oestrogenic metabolites in the human. ${ }^{6}$ This compound significantly increases serum iron and T.I.B.C., but has no effect on serum copper.

Our findings strongly suggest that oral oestrogens have no marked effects on serum iron and T.I.B.C., but that oral progestogens stimulate an increase. This finding is in contrast to the conclusion of Dr. Powell and others, who used intramuscular medroxy-

\title{
Skin Disease and the Gut
}

SIR,-In your leading article (1 August, p. 240) you refer to the evidence originally presented by Professor S. Shuster's team ${ }^{1}$ that psoriasis may be associated with an abnormality of the intestinal mucosa. You suggest that lack of confirmation of these results by other observers implies that the original findings were at fault due to derivation of the groups of patients and controls from different population areas. In their latest publication on this subject Dr. Marks and Professor Shuster ${ }^{2}$ themselves argue this case persuasively. They show that the incidence of stereomicroscopic abnormalities found in jejunal biopsies from patients with psoriasis in the Newcastle upon Tyne area is no different from that found in control subjects from the same area.

There are, of course, more ways than one of demonstrating the presence of an enteropathy, and only some of these were progesterone acetate. A possible explanation of this difference is the route of administration of the steroid. The changes in blood constituents are probably secondary to effects on the liver synthesis and release of metal-binding proteins. Oral steroids are absorbed into the entero-hepatic circulation and probably reach the liver in far higher $\omega$ concentrations than if given by the intramuscular route. We must also point out that medroxyprogesterone acetate, while devoid of oestrogenic properties, has up to one third of the glucocorticoid activity of hydrocortisone in the human. ${ }^{7}$ The effect of corticoid-sex hormone interactions on trace element binding proteins in blood is not yet $\tilde{0}$ known.

We are grateful for the assistance in this work of Dr. J. Austin, Dr. Denise Pullen, Mr. J. E. N. Kelly, and the staff of the Wandsworth F.P.A. Clinic.-We are, etc.,

M. H. BRIGGS. MAXINE BRIGGs.

Department of Biochemistry University of Zambia,

RefBrencrs

1 Briggs, M., and Staniford, M., Lancet, 1969, 2, 742. M. U., Doe, R. P., and Seal, U. S., foum of Clinical Endocrinology and Metabolism, 1967, $27,1463$.

3 Zilva, J. F., Lancet, 1969, 2, 847. Foumal of Clinical Endocrinology and Metabolism, 1969, 29, 1489.

Briggs, M. H.; Austin, J., and Staniford, M. Littleton, P.; Fotherby, K., and Dennis, K. J., Fournal of Endocrinology, 1968, 42, 591. Simon, S., Schiffer, M., Glick, S. M., and

Schwartz, E. Fournal of Clinical
and Metabolism, 1967, 27, 1633.

used by the same workers in their investigation of "dermatogenic enteropathy." $3 \mathrm{We}^{4}$ have correlated jejunal mucosal morphology and disaccharidase activities with the results of a lactose tolerance test, glucose/galactose tolerance test, lactose barium meal, and xylose absorption test in 14 patients with psoriasis. There was evidence of an enteropathy in two-thirds of cases. The mucosal lesion appeared extensive in some cases, but it was never severe. Partial villous atrophy was seen but never a completely flat mucosa. Half the patients showed reduction of mucosal disaccharidase levels. Other parameters were abnormal in some cases.

Our (unpublished) findings among control subjects, using these same parameters, show a very much lower incidence of abnormalities. Moreover, most of the individuals we have investigated were serving members of 